\title{
Rutas y encrucijadas: cronotopos de la narrativa contemporánea latinoamericana
}

\author{
Estefanía BOURNOT \\ bournot@uni-potsdam.de \\ Universidad de Potsdam
}

\begin{abstract}
RESUMEN
El actual marco global ha determinado la construcción de nuevos espacios ficcionales que desestabilizan las estructuras binarias desde las cuales se enfocó la literatura latinoamericana. Si en otra época se trataba de una pugna cultural entre campo y ciudad, autóctono o extranjerizante, civilización o barbarie; hoy en día es casi imposible discernir dónde se encuentran las fronteras entre lo local y lo global, pues también el imaginario literario se ha expandido a escalas mundiales en busca de nuevos paisajes. A partir de obras narrativas recientes de Guillermo Fadanelli, Andrés Neuman y Lina Meruane este artículo indaga en las formas de entender el tiempo y el espacio en la literatura contemporánea de Latinoamérica.
\end{abstract}

Palabras clave: espacio, paisaje, cronotopo, heterotopía, narrativa contemporánea.

Routes and crossroads: chronotopes of the Latin American contemporary narrative

\begin{abstract}
The contemporary global social landscape has fostered the construction of new fictional spaces, which have destabilized the binary structures that were previously used to approach Latin American literature. Whereas in the past, literary analysis was based on a cultural dichotomy between the countryside and urban spaces, the local and the foreign, civilization and barbarism, today it is almost impossible to determine where the boundaries between the local and the global are, because the literary imaginary has increasingly acquired international dimensions, in search of new horizons. Through the analysis of recent narrative works by Guillermo Fadanelli, Andrés Neuman and Lina Meruane, this article studies how contemporary Latin American literature understands time and space.
\end{abstract}

Keywords: landscape, space, chronotope, heterotopia, contemporary narrative.

SUMARIO: 1. El campo y el mundo 2. Crisis del paisaje 3.Cronotopos contemporáneos 4. Mapas de rutas

\section{El campo y el mundo}

Entrando al nuevo milenio, la editorial Mondadori, una de las más grandes del mercado en lengua española, encargó a siete jóvenes escritores lo que en un princi- 
pio debía ser una serie de libros de viaje y que finalmente acabaría por conformar la colección Año cero, con novelas de nombres tan ineludibles para la literatura hispanoamericana contemporánea como Rodrigo Fresán, Roberto Bolaño o Santiago Gamboa, entre otros. La consigna era simple: a cada escritor se le financiaba una estadía en una ciudad sobre la cual debían escribir. Los destinos escogidos abarcaban los puntos más distantes del globo: Pekín, El Cairo, Moscú, Roma, México D.F., Nueva York y Londres. La colección que abría un nuevo milenio para las letras hispanoamericanas lo hacía marcando ya un signo distintivo: la expansión.

Tal y como indica el título Año cero, se trataba, al menos como estrategia de marketing editorial, de un nuevo comienzo, de un borrón y cuenta nueva. Las palabras de José Manuel Prieto, uno de los autores que participó, son elocuentes: "Se trata de un ramillete de obras que muestran la visión de autores iberoamericanos sobre el mundo. Una inversión, en esencia, de sujetos observados, como había sido inveteradamente, a observadores sagaces e inteligentes de las principales urbes del planeta en el año 2000" (2011: 16).

Pocos años después la iniciativa de Mondadori tuvo una réplica ampliada a 17 escritores de Brasil, donde otra casa editorial de gran peso, la Companhia das Letras, creó la colección Amores Expressos, la cual además de la publicación de novelas comprendía toda una campaña de imagen, que incluía la edición regular de un blog por parte de los autores mientras estuvieran en el extranjero, tráileres de cada una de las obras y posteriores adaptaciones cinematográficas.

Ambas colecciones además de ilustrar de forma bastante evidente algunas de las nuevas políticas de mercado y mecenazgo editoriales que hoy en día son cada vez más comunes, vienen a constatar una intensificación de las dinámicas globales que exigen no solo una ampliación de las redes de distribución de bienes culturales sino también la expansión del mismo espacio ficcional. Se trata, como lo explica Prieto, de una "inversión" de la perspectiva, en la que los autores pasan de ser objetos exóticos en el punto de mira de la cultura occidental a ser "sagaces observadores" que no se conforman con el autorretrato, sino que quieren ofrecer una visión propia del mundo, un mundo que se expande a sus pies y en cuya expansión toma partido también la letra escrita.

Si durante el siglo XX los debates sobre la 'transculturación', la 'heterogeneidad' e 'hibridación' giraban en gran parte en torno al modo en que la literatura latinoamericana recibía y se apropiaba de las influencias extranjeras en busca de un estilo propio, hoy la cuestión de una autonomía estética parece darse por superada, pues ya no se trata de crear una identidad literaria representativa, o de filtrar o tamizar esas influencias foráneas, sino todo lo contrario, hay una búsqueda intencionada de nuevas influencias y modelos alternativos. La literatura desestabiliza la cartografía volviendo permeables y móviles las fronteras. Me interesa por tanto analizar cómo desde la ficción se promueven poéticas del espacio en el imaginario social que cuestionan y alteran los paradigmas de alteridad e identidad establecidos. 


\section{Crisis del paisaje}

Hace un siglo Alfonso Reyes describía en su Visión de Anahuác (1917) el sentimiento exaltado de comunión con el paisaje como base de la identidad del pueblo mexicano. Al no compartir un origen cultural y étnico común, lo que une a los habitantes de esta nación, según el texto, es la fuerza cohesionadora del mismo escenario natural en el que habitan:

Nos une con la raza de ayer, sin hablar de sangres, la comunidad del esfuerzo por domeñar nuestra naturaleza brava y fatigosa; esfuerzo que es la base bruta de nuestra historia. Nos une también la comunidad, mucho más profunda, de la emoción cotidiana ante el mismo objeto natural. El choque de la sensibilidad con el mismo mundo labra, engendra un alma común. (Reyes, 2004: 37)

Precisamente en contra de esta noción de esencialidad de lo latinoamericano como una cualidad aferrada a la tierra es que escriben muchos de los autores hoy en día. El paisaje como eje estructurador de una identidad, de un "alma común" y como componente necesario para ser leído como autor latinoamericano fue una de las críticas del prólogo de Alberto Fuguet y Sergio Gómez en la antología McOndo (1996) a la que se sumaron posteriormente un gran número de autores ${ }^{1}$.

El debate, alimentado tanto por autores como por la crítica, acerca del posicionamiento de la literatura hispanoamericana entre lo local y lo global quedó reducido, en gran parte debido al prólogo de la antología de $M c O n d o$, a un distanciamiento o lucha por diferenciarse de la literatura canonizada del boom y del realismo mágico. Las diferencias generacionales se tornaron en una confrontación dialéctica entre regionalistas y cosmopolitas, que ya tiene una larga tradición en Latinoamérica (Siskind, 2014): de un lado una narrativa centrada en la realidad rural, tropical, vinculada a los ideales políticos de la revolución, y del otro lado, un nuevo tipo de literatura calificada de cosmopolita, universal, urbana, centrada en "realidades individuales y privadas" . Si bien es evidente que la literatura de las últimas décadas ha ampliado el marco de referencia hacia fuera de los límites del estado-nación, no

${ }^{1}$ En el discurso de entrega del Premio Alfaguara de Novela en 2010, Andrés Neuman pronunciaría las siguientes palabras: "La literatura en español puede aspirar, al igual que otras grandes literaturas (como la norteamericana) u otras lenguas (como el francés o el alemán), a simbolizar cualquier espacio, a ser una metonimia del mundo. Puede que, desde los años '90, la sensación de muchos nuevos autores sea esa: el desprejuicio territorial" (Neuman, 2010: 544).

2 "Los cuentos de $\mathrm{McOndo}$ se centran en realidades individuales y privadas. Suponemos que esta es una de las herencias de la fiebre privatizadora mundial. Nos arriesgamos a señalar esto último como un signo de la literatura joven hispanoamericana, y una clave de entrada a este libro. [...] [Los cuentos] no son frescos sociales ni sagas colectivas" (Fuguet y Gómez, 1996: 13) 
significa que por ello queden anulados los vínculos con lo local, sino que lo local ya no es mero aferramiento al suelo, sino una forma de entender, de sentir, de imaginar, que puede estar atravesada, influenciada y proyectada hacia varios y diferentes paisajes. Lo local, que en este caso es América Latina ya no se autopresenta como periférico ni intenta autodefinirse para los demás, sino que expone su propio potencial creativo sin necesidad de justificarse ${ }^{3}$.

Como dejan entrever las colecciones editoriales mencionadas anteriormente, "la nueva literatura remite a nuevas comunidades discursivas, algunas en la red, que ya no dependen de puntos de origen canónicos" - señala el crítico Román De la Campa (2011: 29). La muerte de la literatura latinoamericana que pregonó Volpi (2004) es cierta, si entendemos Latinoamérica como un territorio y no como una epistemología. Cuando gran parte su población vive fuera del continente o se desplaza constantemente por los flujos migratorios, el comercio, el turismo, o cuando incluso sin desplazarnos accedemos a través de las redes de comunicación a gran parte de la vasta cultura mundial, parece cada vez más necesaria una ampliación del paisaje más que en un sentido territorial, en un sentido semántico, como lugar de enunciación, un marco o una perspectiva que no está necesariamente aferradas al suelo sino que se abren desde una mirada que puede estar múltiplemente posicionada (migrantes, viajeros...) y conectada a redes que se bifurcan y extienden infinitamente.

\section{Cronotopos contemporáneos}

En contrapartida a la nueva avalancha de novelas que, como en las colecciones mencionadas de Mondadori y Companhia das Letras, sitúan la trama en lugares distantes a Latinoamérica, privilegiando un imaginario expansivo e incluso exotizante de otras regiones del mundo ${ }^{4}$, me gustaría centrarme en novelas de autores hispanoamericanos que, dentro del marco local, crean figuras espaciales a partir de un imaginario global transnacional. Estas novelas dan una pista de cómo la literatura reelabora poéticamente algunas nociones estáticas como la de identidad, cultura y nación, privilegiando espacios de contacto y figuras móviles.

Tal es el caso de la novela de Guillermo Fadanelli, Hotel DF (2011), que, como el mismo título indica, toma el hotel como espacio de flujo y convergencia en el que

3 "Lo nacional ha devenido tanto en su composición interna como en sus relaciones con el exterior menos el lugar en que se produce de una vez y para siempre una identidad nacional y más aquel lugar en que se negocia permanentemente la interculturalidad interna y externa; en segundo lugar, las poblaciones nacionales se han reterritorializado e incluyen ahora cantidades significativas de connacionales viviendo más o menos permanentemente en el extranjero; por último ha surgido un fuerte movimiento recuperador de la dimensión regional-global latinoamericana como mediación apropiada de las relaciones entre la nación y el mundo" (Poblete, 2006: 287-288).

${ }^{4}$ Hoyos (2015); López-Calvo (2009), López-Calvo (2012). 
se concentran algunas de las dinámicas más características de la era global percibida desde la especificidad del D.F. El hotel, por ser precisamente un lugar de paso, de estancia temporal y generalmente frecuentado por una amplia variedad de gentes de diferentes proveniencias e intereses, podría ser uno de los cronotopos paradigmáticos de la globalización, si entendemos cronotopo como la "concreción plástica dentro de la obra de arte del tiempo y el espacio", tal y como lo definió Bajtín (1991: 237).

A su vez, el hotel es definido por Marc Augé como uno de los no-lugares emblemáticos de la posmodernidad, por ser un espacio de tránsito que no se atiene a ninguna historicidad propia ni contiene rasgos originales específicos ${ }^{5}$. Sin embargo, precisamente por ser un espacio sin delimitaciones claras, sirve como una hoja en blanco donde los autores pueden crear un mundo con reglas propias que no necesariamente se corresponden con las de la cultura normativizada y oficial. El hotel actúa muchas veces en el relato como reproducción en miniatura de una realidad global contenida en el espacio local que contribuye a alimentar el discurso cosmopolita no mediante una expansión sino mediante una concentración. No casualmente se publican el mismo año Hotel España (2010) de Juan Pablo Meneses y Cómo viajar sin ver, de Andrés Neuman, dos ejemplos de literatura de viaje en las que el hotel es el escenario principal, como también en Necrópolis (2009) u Hotel Pekín (2008), ambas novelas de Santiago Gamboa, por dar algunos ejemplos.

El escenario de encrucijadas permite a los autores organizar el relato de forma polifónica, donde cada voz tiene un lugar y donde el lugar se presta al diálogo, al encuentro e incluso al choque de culturas. Precisamente por esta acumulación de historias que se van entrelazando y superponiendo, el hotel se constituye como un palimpsesto, un espacio de múltiples discursos, que en vez de un no-lugar, puede ser todos-los-lugares al mismo tiempo.

En la novela de Fadanelli, coinciden en el hotel Isabel, tanto visitantes locales, representantes de todas las clases y rubros, traficantes, periodistas, artistas, así como turistas extranjeros que exaltan y a la vez relativizan los rasgos diferenciales de la mexicanidad. Una mexicanidad que no puede asumirse como una unidad homogénea. Desde la mirada cínica y un tanto sarcástica de Fadanelli, ese "nosotros" supone una inmensa gama de diferenciaciones, muchas veces cargadas de racismo, prejuicios y (auto)discriminaciones:

Miro al Boomerang Riaño con detenimiento, sus quijadas paleolíticas, su vejez prematura, ¿qué tribu del Amazonas lo reconocería como miembro permanente? [...] "nosotros". ¿Cómo se atreve el jodido analfabeta, oreja, Rasputín de pacotilla, madrina de mierda, a decir "nosotros"? (Fadanelli, 2011:71)

\footnotetext{
${ }^{5}$ Augé (2000).
} 
El narrador del Hotel DF está más comprometido con acentuar la diferencia, que con exaltar la identidad mexicana. Su intención es abrir una brecha en el "nosotros" tanto de las fronteras nacionales para dentro como de México para afuera. El hotel es para el autor una puerta abierta a la alteridad, una "heterotopía", en términos foucaultianos: un lugar que refleja lo que es la sociedad al mismo tiempo que la contradice, la forma topológica por la cual se delimita un "otro" que queda excluido, apartado o marginalizado del discurso normativo de una sociedad.

El artista Henestrosa, que es la voz que hila el relato desde las diferentes perspectivas de los huéspedes, ve en el hotel la posibilidad de escapar de la realidad del D.F. por unos días para vivir entre refinados europeos, consciente de que la convivencia, aunque sea de manera superficial y por unos pocos días, lo confrontará con sus propios prejuicios:

Nunca he estado en Europa. ¿Yo, el artista Henestrosa cruzando el mar? Ni pensarlo. Sin embargo, hoy más que nunca necesito rodearme de personas educadas, ecologistas, refinadas, y olvidarme de vivir en un sartén manipulado por el diablo. No soy tan idiota como para pensar que todos los europeos son tal y como los he descrito, pero me conviene pensar así, ¡me conviene! Y no iré a su continente solo para decepcionarme. Aquí me quedo. Dentro de mi cabeza suceden misteriosos acontecimientos, las imágenes se desplazan sin muletas a velocidades desquiciadas y nada puede estar tan podrido en mi vida si a unas cuadras existe un hotel como el Isabel. Invadiré Europa sin subirme a un avión. (Fadanelli, 2011: 20)

Esta última imagen de un mexicano invadiendo Europa subvierte los paradigmas culturales de la colonización. El cliché del europeo como sinónimo de la civilización y la cultura es caricaturizado y cuestionado, del mismo modo que la barbarie del pueblo llano mexicano. Así, por ejemplo, la mucama encargada de la limpieza exclama al encontrarse con un huésped alemán recostado en el suelo tras una noche de borrachera: "El señor no siente pena de acostarse en el suelo cuando podría acomodarse en uno de los sillones de la recepción, estas cosas deben ser normales en sus países, pero están en México, donde somos pobres y tenemos modales" (Fadanelli, 2011: 28). El turista alemán, supuesto embajador de la civilización europea, se arriesga sin miedo a los barrios y locales peligrosos del D.F. en busca de aventura y del color local que se supone deberían brindarle esas latitudes: "El Von Humboldt barriobajero explorador, sabio y buscador de nuevas especies, ha creído encontrar un antro del tamaño de su melancolía" (Fadanelli, 2011: 171).

La experiencia de la diferencia somete a toda cultura a una expropiación constante y a la imposibilidad de cerrarse sobre sí misma. Los habitantes del D.F. -"mexicanos autóctonos"- ven en el paso por el hotel un ejercicio de extrañamiento, un distanciamiento de sí mismos. En la novela se hace evidente que los paradigmas de la alteridad se encuentran tanto dentro como fuera de la misma ciudad, pues el solo hecho de cambiar de barrio puede suponer la entrada a un mundo radi- 
calmente nuevo. Gabriel Sandler, artista de fama mundial y adinerado habitante de los barrios de clase alta del D.F., experimenta la visita al centro como si fuera Colón descubriendo América, como un viaje exótico:

El Centro: un mundo nuevo para Gabriel, quien contempla azorado cómo esa ciudad se le revela paso a paso. [...] Embarga al chico una sensación emocionante, ser extranjero en su tierra, sí, estar en oriente sin haber dado más que unos pocos pasos, la orfandad repentina que nutrirá su siguiente obra: es un afortunado, sin duda. (Fadanelli, 2011: 66-67)

Aquí nuevamente se revierten las referencias espaciales de occidente y oriente. Desde la perspectiva de Sandler, el centro del D.F. es un territorio ignoto donde él es extranjero y, precisamente por eso, este espacio resulta estimulante y nutritivo. La dualidad y ambigüedad de estas relaciones ponen de manifiesto el carácter ficcional de dicho espacio, que es uno y varios al mismo tiempo según la perspectiva que se asuma. El mismo escenario del D.F. y del hotel, que vendría a ser una analogía en miniatura, concentran en sí varias ciudades, varios orientes y occidentes, que como un caleidoscopio varían de diseño y forma.

\section{Mapas de rutas}

Al igual que el hotel, toda la nación puede ser vista como un lugar de paso, como una encrucijada de caminos que coinciden en un espacio y un tiempo determinados pero que siguen expandiéndose y creando nuevas configuraciones. Así lo presenta la novela de Andrés Neuman Una vez Argentina (2003), que más que un árbol genealógico de su familia, es un mapa de rutas. En ella emerge una imagen de la patria natal del autor, vista como un espacio móvil, atravesado por flujos migratorios, por las idas y venidas de los numerosos integrantes de su familia. No se trata de un macrorrelato de la historia nacional contado a partir de una saga familiar, sino de episodios sueltos, esbozos de caracteres que proyectan diferentes ópticas sobre los vínculos y encrucijadas que se dieron en torno a un espacio compartido.

Comenzando por los lejanos bisabuelos de origen judío llegados desde la Europa oriental hasta la reciente migración de sus propios padres a España en la década de los 90, Neuman presenta a modo de mosaico historias superpuestas que juegan a ensanchar las fronteras de la patria, que ya no está fijada a un territorio sino que pasa más bien por los lazos familiares y afectivos que se establecen a lo largo de la vida:

Son un puñado de seres anónimos los que terminan de formar nuestras familias verdaderas. Personas que aparecen y desaparecen. Incluso algunas que encontramos durante un instante. Son las casualidades, el azar, los accidentes con fortuna, nuestra familia desolada. (Neuman, 2003: 147) 
Neuman saca a relucir la inestabilidad de ciertas nociones estáticas del hogar, la familia, la nación, y las sitúa sobre una línea contingente en la que se conjugan la fragilidad del tiempo y la accidentalidad del paisaje. Así, los personajes que pueblan su narrativa son siempre extranjeros, pasajeros en tránsito de su propio destino. Es el caso de Martín Kovensky, uno de los primos, quien arrastrado por sus padres al exilio en São Paulo durante la dictadura argentina en los años 70, vuelve más tarde a Buenos Aires, donde jamás se instala definitivamente, más bien lo contrario, inicia una dinámica de desplazamiento incesante:

La nostalgia de Martín Kovensky no tenía tanto que ver con la idea de volver a los lugares, como con la idea de salir de ellos. De todos los nietos que tuvo el zeide Jonás, benefactor de la comunidad, sin duda el más judío ha sido él. Si su primera emigración fue forzada, lo cierto es que ésta pareció poner en marcha un remoto mecanismo errante que alcanzaría no solo su afición por los viajes repentinos, sino también su costumbre de mudarse de casa con compulsiva frecuencia. Para Martín las casas no eran tanto una invitación al reposo como la antesala de una diáspora. (Neuman, 2003: 209)

De manera similar a esta visión nómada que ofrece Neuman, el escritor franco libanés Amin Maalouf desarrolla una perspectiva sobre las nociones de tradición literaria y nación, en contra de imágenes de la pertenencia y su habitual contrapartida, el desarraigo ${ }^{6}$. El escritor comienza su libro de memorias Origines (2006), en el que como Neuman despliega la historia de su extensa familia, redirigiendo la metáfora de las raíces hacia otra más dinámica y polivalente: las rutas. Para el autor se trata de poner en cuestión el concepto de cultura como organismo aferrado al suelo y de verlo en su potencial de movilidad y transformación con el fin de que prevalezcan los aspectos más productivos e inclusivos. Así vemos las fronteras no como obstáculos sino como figuras liminares, que ponen en contacto territorios, que dan inicio a un recorrido.

Un recorrido que puede llevar a varios destinos y que puede tener múltiples orígenes, tal y como lo plantea también la autora chilena Lina Meruane en su libro Volverse Palestina (2013), donde intenta reconstruir la parte de su identidad chilena que está ligada a la historia del pueblo palestino. Una identidad que la narradora intenta recrear como un posible "origen compartido de la extinción" (Meruane, 2013: 6) y que asume como un regreso, "volveres prestados" a algo que ya no le pertenece, o tan solo en parte, pues "Él, [padre]como antes sus padres la Beit Jala natal, abandonó hace mucho tiempo la pequeña ciudad-de-provincia donde nació. Y yo, como ellos, me largué también" (Meruane, 2013: 16).

${ }^{6}$ Ver: "Cartografías móviles de la patria. Amin Maalouf, la problemática del exilio y el saber con/vivir de las literaturas sin residencia fija”. En: Ette (2009: 167-212) 
Tanto Meruane como Neuman sacan a la luz una serie de caminos recorridos que en conjunto recrean un paisaje de encrucijadas, como el hotel, a partir del cual las rutas siguen expandiéndose y bifurcándose. Estas poéticas nómadas absuelven la concepción bipartita de la literatura latinoamericana entre un "afuera" y un "adentro" buscando aquellos puntos de encuentro, esos espacios paradigmáticos de la contemporaneidad que dan lugar a un "nosotros" menos compacto y más heterogéneo. Quizás en eso consista la labor de los narradores latinoamericanos hoy: trazar posibles orígenes compartidos de la extinción.

\section{BIBLIOGRAFÍA}

AugÉ, Marc.

2000 Los "no lugares", espacios del anonimato. Una antropología de la sobremodernidad. Barcelona: Gedisa.

DE LA CAMPA, Román.

2011 "El Caribe y su apuesta teórica", en SUR/Versión, núm. 1, pp. 2552.

ETTE, Ottmar.

2009 Del macrocosmos al microrrelato. Literatura y creación: nuevas perspectivas transareales. Guatemala: F \& G Editores.

FADANELLI, Guillermo.

2011 Hotel DF. Barcelona: Mondadori.

FOUCAULT, Michel.

2008 “Topologías”, en Fractal, núm. 48, pp. 39-40.

FugUET, Alberto y Sergio GóMEZ (eds.).

Hoyos, Héctor.

1996 McOndo. Barcelona: Mondadori.

2015 Beyond Bolaño. The global Latin American novel. New York: Columbia Univ. Press.

LÓPEZ-CALVO, Ignacio (ed.).

2009 One World Periphery Reads the Other: Knowing the "Oriental" in the Americas and the Iberian Peninsula. Newcastle, UK: Cambridge Scholars Publisher.

2012 Peripheral transmodernities. South-to-south interculturaldialogues between the Luso-Hispanic world and 'the Orient'. Newcastle UK: Cambridge Scholars Pub.

MAALOUF, Amin.

2006 Origines. Paris : Librairie générale française.

MERUANE, Lina.

2013 Volverse Palestina. México, D.F.: Literal Publishing. 
NEUMAN, Andrés.

2003 Una vez Argentina. Barcelona: Anagrama.

2010 "Ficticios, sincronizados y extraterrestres. Discurso de recepción del Premio Alfaguara 2009", en Andrés Neuman (ed.), Cómo viajar sin ver. Madrid: Santillana, pp. 537-546.

POBLETE, Juan.

2006 "Globalización, mediación cultural y literatura nacional", en Sánchez Prado, Ignacio M. (ed.), América Latina en la "literatura mundial". Pittsburgh: Inst. Internacional de Literatura Iberoamericana, pp. 271-306.

PRIETO, José Manuel.

2013 “"Treinta días en Moscú'. La escritura de un libro de viajes”, en Caracol (São Paulo), núm. 3, pp. 10-26.

REYES, Alfonso.

2004 "Visión de Anáhuac", en Visión de Anáhuac y otros ensayos. México, D.F.: Fondo de Cultura Económica.

SISKIND, Mariano.

2014 Cosmopolitan desires. Global modernity and world literature in Latin America. Evanston, Illinois: Northwestern University Press.

VOLPI ESCALANTE, Jorge.

2004 "El fin de la narrativa latinoamericana", en Palabra de América. Barcelona: Seix Barral, pp. 206-223. 